\title{
Correction \\ Correction: Garcia et al. Primary Model for Biomass Growth Prediction in Batch Fermentation. Symmetry 2021, 13, 1468
}

\author{
Blanca E. Garcia ${ }^{1}\left({ }^{-}\right.$, Emmanuel Rodriguez ${ }^{2}\left(\mathbb{D}\right.$, Yolocuauhtli Salazar ${ }^{2, *}(\mathbb{C})$, Paul A. Valle ${ }^{3, *(\mathbb{D},}$ \\ Adriana C. Flores-Gallegos ${ }^{1} \mathbb{D}$, O. Miriam Rutiaga-Quiñones ${ }^{4}(\mathbb{D})$ and Raul Rodriguez-Herrera ${ }^{1}(\mathbb{D})$ \\ 1 Food Research Department, School of Chemistry, Universidad Autónoma de Coahuila, C. José Cárdenas \\ Valdez and Av. Venustiano Carranza, Saltillo 25280, Mexico; bgarcia@itdurango.edu.mx (B.E.G.); \\ carolinaflores@uadec.edu.mx (A.C.F.-G.); raul.rodriguez@uadec.edu.mx (R.R.-H.) \\ 2 Postgraduate Program in Engineering, Tecnológico Nacional de México/IT Durango, Blvd. Felipe Pescador \\ 1830 Ote., Durango 34080, Mexico; 10040780@itdurango.edu.mx \\ 3 BioMath Research Group, Postgraduate Program in Engineering Sciences, Tecnológico Nacional de México/IT \\ Tijuana, Blvd. Alberto Limón Padilla s/n, Tijuana 22454, Mexico \\ 4 Department of Chemical and Biochemical Engineering, Tecnológico Nacional de México/IT Durango, \\ Blvd. Felipe Pescador 1830 Ote., Durango 34080, Mexico; omrutiaga@itdurango.edu.mx \\ * Correspondence: ysalazar@itdurango.edu.mx (Y.S.); paul.valle@tectijuana.edu.mx (P.A.V.)
}

check for updates

Citation: Garcia, B.E.; Rodriguez, E.;

Salazar, Y.; Valle, P.A.;

Flores-Gallegos, A.C.;

Rutiaga-Quiñones, O.M.;

Rodriguez-Herrera, R. Correction:

Garcia et al. Primary Model for

Biomass Growth Prediction in Batch

Fermentation. Symmetry 2021, 13,

1468. Symmetry 2022, 14, 19. https://

doi.org/10.3390/sym14010019

Received: 29 November 2021

Accepted: 2 December 2021

Published: 24 December 2021

Publisher's Note: MDPI stays neutral with regard to jurisdictional claims in published maps and institutional affiliations.

Copyright: () 2021 by the authors. Licensee MDPI, Basel, Switzerland. This article is an open access article distributed under the terms and conditions of the Creative Commons Attribution (CC BY) license (https:// creativecommons.org/licenses/by/ $4.0 /)$.

\section{Addition of Authors}

The authors wish to make the following corrections to this paper [1]. Adriana C. FloresGallegos, O. Miriam Rutiaga-Quiñones and Raul Rodriguez-Herrera were not included as authors in the original publication. The corrected Author's Contributions Statement, Funding and Acknowledgments appears here. The authors apologize for any inconvenience caused state that the scientific conclusions are unaffected. The original publication has also been updated.

\section{Origin form:}

Yolocuauhtli Salazar ${ }^{1, *}$, Emmanuel Rodriguez ${ }^{1,}$ Paul A. Valle ${ }^{2, *}$ and Blanca E. Garcia ${ }^{3}$

1 Postgraduate Program in Engineering, Tecnológico Nacional de México/IT Durango, Blvd. Felipe Pescador 1830 Ote., Durango 34080, Mexico; 10040780@itdurango.edu.mx

2 BioMath Research Group, Postgraduate Program in Engineering Sciences, Tecnológico Nacional de México/IT Tijuana, Blvd. Alberto Limón Padilla s/n, Tijuana 22454, Mexico

3 Department of Chemical and Biochemical Engineering, Tecnológico Nacional de México/IT Durango, Blvd. Felipe Pescador 1830 Ote., Durango 34080, Mexico; bgarcia@itdurango.edu.mx

* $\quad$ Correspondence: ysalazar@itdurango.edu.mx (Y.S.); paul.valle@tectijuana.edu.mx (P.A.V.)

\section{Correct form:}

Blanca E. Garcia 1, Emmanuel Rodriguez ${ }^{2}$, Yolocuauhtli Salazar ${ }^{2, *}$, Paul A. Valle ${ }^{3, *}$, Adriana C. Flores-Gallegos ${ }^{1}$, O. Miriam Rutiaga-Quiñones ${ }^{4}$ and Raul Rodriguez-Herrera ${ }^{1}$

1 Food Research Department, School of Chemistry, Universidad Autónoma de Coahuila, C. José Cárdenas Valdez and Av. Venustiano Carranza, Saltillo 25280, Mexico; bgarcia@itdurango.edu.mx (B.E.G.); carolinaflores@uadec.edu.mx (A.C.F.-G.); raul.rodriguez@uadec.edu.mx (R.R.-H.)

2 Postgraduate Program in Engineering, Tecnológico Nacional de México/IT Durango, Blvd. Felipe Pescador 1830 Ote., Durango 34080, Mexico; 10040780@itdurango.edu.mx

3 BioMath Research Group, Postgraduate Program in Engineering Sciences, Tecnológico Nacional de México/IT Tijuana, Blvd. Alberto Limón Padilla s/n, Tijuana 22454, Mexico 
4 Department of Chemical and Biochemical Engineering, Tecnológico Nacional de México/IT Durango, Blvd. Felipe Pescador 1830 Ote., Durango 34080, Mexico; omrutiaga@itdurango.edu.mx

* Correspondence: ysalazar@itdurango.edu.mx (Y.S.); paul.valle@tectijuana.edu.mx (P.A.V.)

Author Contributions: Conceptualization, Y.S., O.M.R.-Q. and R.R.-H.; methodology, Y.S. and E.R.; software, P.A.V.; validation, Y.S., B.E.G. and P.A.V.; formal analysis, Y.S. and P.A.V.; investigation, E.R. and A.C.F.-G.; resources, B.E.G.; data curation, B.E.G.; writing-original draft preparation, Y.S. and E.R.; writing-review and editing, P.A.V.; visualization, Y.S. and P.A.V.; supervision, Y.S. and P.A.V.; project administration, Y.S. All authors have read and agreed to the published version of the manuscript.

Funding: Authors of this work were supported by different projects indicated as follows: Yolocuauhtli Salazar by the TecNM project 10083.21-P: Modelizado de la dinámica de crecimiento de microorganismos durante la fermentación de leche fresca with number; Paul A. Valle by the TecNM project 9951.21-P Modelizado computacional y experimentos in silico aplicados al análisis y control de sistemas biológicos; Blanca E. Garcia and O. Miriam Rutiaga-Quiñones by the TecNM project 5973.19-P Desarrollo de un potencial inoculante para la producción de Jocoque.

Acknowledgments: Emmanuel Rodriguez and Blanca E. Garcia express their recognition to the National Council of Science and Technology of Mexico (Consejo Nacional de Ciencia y Tecnología, CONACyT) for the financial support during their postgraduate studies under their scholarship agreement.

\section{Reference}

1. Garcia, B.E.; Rodriguez, E.; Salazar, Y.; Valle, P.A.; Flores-Gallegos, A.C.; Rutiaga-Quiñones, O.M.; Rodriguez-Herrera, R. Primary Model for Biomass Growth Prediction in Batch Fermentation. Symmetry 2021, 13, 1468. [CrossRef] 